\title{
DOE/ER/40150 - 340 \\ A 20 AMPERE SHUNT REGULATOR FOR \\ CONTROLLING INDIVIDUAL MAGNETS IN A SERIESED STRING
}

\author{
E. J. Martin, N. Dobeck, G. S. Jones, M. K. O'Sullivan,
Continuous Electron Beam Accelerator Facility, Newport News, VA 23606 USA \\ JUL 251996 \\ At the CEBAF accelerator, groups of dipole magnets

\section{DESIGN APPROACH}

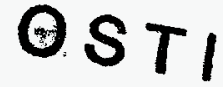
are often connected together in series and powered from a single large constant-current regulated DC supply, referred to locally as a "box" supply. Besides the economy realized, this configuration promotes correct field tracking of all elements of a beam transport channel. However, it is often desirable to vary the current in one element of a string independently of the others, particularly at the entrance and exits of transport channels. A 20 ampere programmable current shunt is described. Installed in parallel with the desired magnet, it permits shunting (bypassing) up to $5 \%$ of the string current around that magnet.

The shunt regulator consists of a bank of MOSFET power transistors operated in linear mode. Regulation of current through the passbank is obtained by feedback from a manganin shunt maintained at a constant temperature for stability. The module is designed for remote operation and provides readbacks of various parameters useful for maintenance. To achieve complete electrical isolation, an onboard microprocessor provides remote communications via an opto-isolated serial data link. Constructional details and initial operating experience with the plug-in shunt are described.

\section{INTRODUCTION}

A prototype 20 Ampere Shunt Regulator was initially described[1]. This paper reports on the implementation and operating results of the production units derived from that prototype. Over one hundred shunt regulator modules have now been installed at CEBAF and are currently operational.

For purposes of economy and convenience in energy tracking, the CEBAF accelerator places up to 40 bending magnets in a series-connected string. Selected magnets in the string are equipped with shunt regulators, which can bypass up to $5 \%$ of full power supply current through that magnet, thus providing a measure of individual adjustment. The shunts use paralleled power MOSFET devices as the pass elements. The current through the passbank is sensed by a precision shunt resistor and linear feedback is used to control the output. Each shunt must be individually programmable \& monitored from control room, be electrically and mechanically robust, and for maintenance purposes must be able to be quickly exchanged. These objectives were successfully achieved with the compact 400 watt plug-in module described.

\footnotetext{
* Supported by U.S. DOE contract DE-AC05-84ER40150
}

The module shunts current around the magnet by varying conduction through a passbank of eight parallel power MOSFET transistors. Each MOSFET stage is contained in an independent local current-feedback loop to insure each parallel stage presents equal gain and load sharing characteristics to the overall feedback loop (See Figure 1). This configuration must be protected against any failure which would cause the stage to "hog" excess current, typically the shorting of the MOSFET junction. Should this occur, a signalling fuse located in series with the MOSFET source lead clears and the blown fuse is reported to the processor. Load current is re-distributed equally amongst the remaining stages. An important characteristic of the chosen topology is that, with the MOSFET's gate-source voltage reduced to zero, it presents a very high impedance. Thus, turning off the control power to the module simply results in zero current flow through the module; a fail-safe mode.

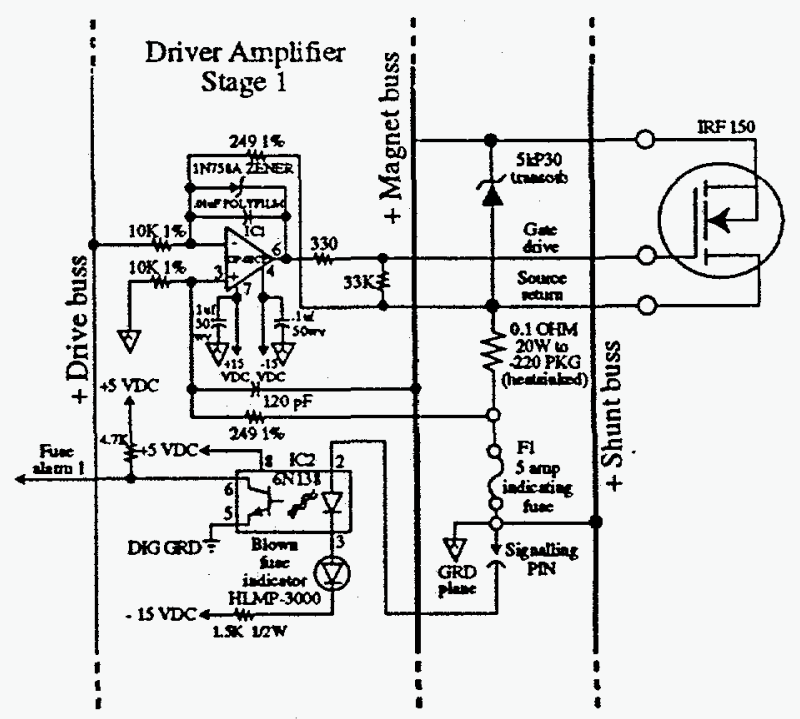

Figure 1: Detailed circuitry of single MOSFET drive stage.

The eight stages are paralleled across the output buss and driven from a common controller amplifier. This amplifier compares signals from a common current measuring shunt and a DAC reference and drives the output stages to achieve constant current regulation of the entire module current (Figure 2). 
This report has been reproduced from the best available copy.

Available to DOE and DOE contractors from the Office of Scientific and Technical Information, P.O. Box 62, Oak Ridge, TN 37831; prices available from (615)576-8401, FTS 626-8401.

Available to the public from the National Technical Information Service, U.S. Department of Commerce, 5285 Port Royal Rd., Springfield, VA 22161.

Price: Printed copy 402 Microfiche 101 


\section{DISCLAIMER}

Portions of this document may be illegible in electronic image products. Images are produced from the best available original document. 


\section{DISCLAIMER}

This report was prepared as an account of work sponsored by an agency of the United States Government. Neither the United States Government nor any agency thereof, nor any of their employees, makes any warranty, express or implied, or assumes any legal liability or responsibility for the accuracy, completeness, or usefulness of any information, apparatus, product, or process disclosed, or represents that its use would not infringe privately owned rights. Reference herein to any specific commercial product, process, or service by trade name, trademark, manufacturer, or otherwise does not necessarily constitute or imply its endorsement, recommendation, or favoring by the United States Government or any agency thereof. The views and opinions of authors expressed herein do not necessarily state or reflect those of the United States Government or any agency thereof. 


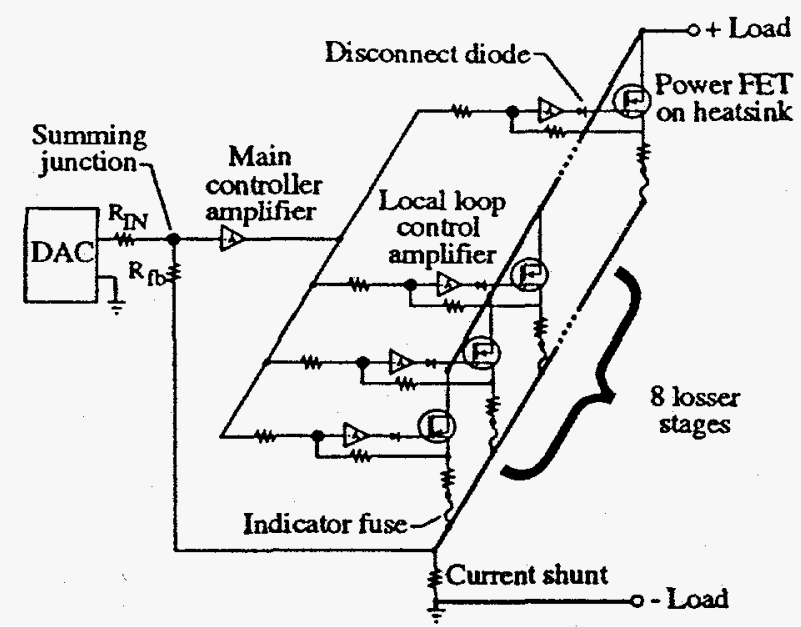

Figure 2: Basic shunt regulator circuit. Each MOSFET has local feedback loop.

The shunt module uses the same Isothermal Controller Module (Highland Model M427) used by the CEBAF trim power supplies[2]. This module contains a manganin shunt, DAC, and reference amplifier integrated on a temperature controlled substrate. Regulation stability of $.05 \%$ per 24 hours is achieved.

Forced air cooling was chosen to simplify the electrical isolation requirements and is achieved using airflow obtained from a blower fan mounted in the top of the rack in which the shunt cardcages are mounted.

The shunt module uses a Motorola MC68701C uP for remote communications, readback of internal levels, and alarm monitoring. The uP and readback circuitry was borrowed intact from the CEBAF trim boards[3]. Only a few lines of code needed to be changed to adapt it to the shunt usage, which shortened the project turn-around. A serial communications interface is used to communicate with the external control network via RS-485 protocol. The link operates full duplex at $76.8 \mathrm{Kbaud}$. Up to 32 shunts may share a common RS-485 link.

\section{ELECTRICAL ISOLATION}

Shunt modules present unique requirements for electrical isolation. Depending where on the magnet string the shunt is electrically connected, it may be required to "float" at up to 600 VDC above Earth Ground. Total electrical isolation from the remote programming source, from other other shunts in the cardcage, and from Earth Ground is required. This isolation is achieved by transformer-isolation of the supply circuits providing control power to the each module and by electrically isolating the modules from the chassis by use of insulated supports and a special connector mounted on G10 laminate.

Isolation for remote programming and readback information is achieved by opto-isolating the RS-485 communications link and three discrete digital control lines. Initial attempts to use $5 \mathrm{KV}$ opto-isolators were unsuccessful, due their slow rise and fall time response characteristics. In order to operate the link at $76.8 \mathrm{Kbaud}$, use of fast opto-isolators (6N138s) was necessary. Since the 6 N138s are rated at only $3 \mathrm{KV}$ breakdown, it was decided to doubly-isolate each signal, passing them through two tiers of opto-isolation. The common circuitry between these two tiers is connected to Earth Ground. Should a voltage surge cause an opto-coupler to break down, the fault current would be intercepted by Earth Ground and not applied across the second tier, possibly causing it to fail as well. As a precaution, all input/output circuits are highpotted to $3 \mathrm{KV} \mathrm{DC}$ after initial assembly of the chassis to insure integrity of isolating circuitry. Connections to a module are via a multipin connector which is isolated from the adjacent module and from chassis ground by mounting it on an insulated bulkhead fabricated from G-10 laminate. To-date, the isolation scheme has worked well. No failures of these circuits to maintain electrical isolation have been reported.

\section{DETAILS OF MODULE CONSTRUCTION}

The shunt module itself is constructed on an 10" $\times 17 "$ finned aluminum extrusion, which serves as a heatsink. The power MOSFET transistors are mounted directly to the heatsink, using sockets to facilitate replacement. The heatsink itself serves as the +LOAD terminal, forming a common connection between the MOSFET cases.

All low level circuitry is contained on three removable circuit boards mounted to the non-finned side of the heatsink. The three boards are interconnected by a wiring harness and plug-in connectors. This facilitates repair-by replacement.

The power supply board contains a common rectifierfilter, from which is developed +24VDC, +15VDC, $+5 \mathrm{VDC},-15 \mathrm{VDC}$, and $-24 \mathrm{VDC}$. Three-terminal linear regulators are used to develop each discrete voltage. The rectifier is fed with $28 \mathrm{VAC}$ from a step-down transformer located off the module in the rear apron of the card-cage chassis. This transformer has $5 \mathrm{KV}$ winding insulation.

The controller board contains the microprocessor, A-Ds, and analog signal conditioning circuitry. Two A-D converters are employed. A 16-bit converter is dedicated to readback of the output current. A 12-bit A-D is multiplexed to monitor output voltage, heatsink temperature, isothermal module temperature, and an auxiliary output current level.

The driver board contains the eight parallel driver stages and the isothermal module. The current sensing resistors connected to each MOSFET source are thermally coupled to the main heatsink using an aluminum bar in a manner similar to that of the power supply module. The common -LOAD buss employs a stamped copper buss bar, soldered perpendicular beneath the driver PCB. 


\section{DETAILS OF CARDCAGE CONSTRUCTION}

The shunt modules are designed to slide into a cardcage-style chassis, making electrical connection by means of a connector mounted on the rear apron of the heatsink. Since the shunt is directly connected to a magnet string with potentials as high as $600 \mathrm{VDC}$ above Earth Ground, safety considerations require that the module be totally enclosed in a chassis whose covers are interlocked to the dipole string power supply.

Unlike a conventional power supply, for the shunt module the hazardous source of power is the box power supply. At CEBAF, the shunt cardcages are often located in entirely different buildings than the box supplies. For this reason, it is necessary to completely interlock the shunt modules and cardcage to that box supply. Removable front and rear chassis covers are interlocked to the box supply to prevent personnel access to the shunt module while the magnet string is energized. Heatsink overtemperature or loss of more than two driver stage fuses will also trip off the box supply.

For safety purposes and ease of interlocking to the box supply, only shunts connected to a common magnet string are housed together in a common chassis. To suit the CEBAF applications, two cardcage packages were developed, a single-chanrel and a four-channel unit.

In the single-channel chassis, the shunt module slides in horizontaily on insulated card guides. Because airflow through the rack is in a vertical sense, an integral linear squirrel-cage fan is employed to force air across the heatsink fins. An integral airflow sensor is interlocked to the box supply to remove power should this fan fail. In the four-channel unit, the modules mount vertically, and air flows directly over the heatsink fins from vents strategically located in the top and bottom chassis covers.

\section{INITIAL OPERATING RESULTS}

From an operational standpoint, the shunts have worked as desired. No unusual or undesirable modes of operation have been experienced. A single module design has sufficed for all applications to date. Field repair of a failed module is accomplished by remove-and-replace, requiring only a few minutes to restore service to a faulted channel. Remote programming and readback, via the RS485 link, has worked without problem-validating the strategy of using the same microprocessor circuitry and software as the time-proven trim cards[3].

There are presently 112 shunt regulators installed and operational at CEBAF. Typically, one module shunts one magnet, however there are eight applications where a module shunts two adjacent magnets in a string. There are
34 four-channel chassis and 11 single-channel chassis installed.

In the past three and one half months, we have accumulated a total of 150,000 module-hours of operation [4]. Six failures have been experienced. These failures were all traceable to workmanship errors in the initial manufacture (pinched wires, poor solder connections, etc.).

\section{REFERENCES}

[1] E. Martin, et al., "Re Use of Common Elements of a Corrector Power Supply Design to Develop A Dissipative Shunt Regulator Design," E. Martin, et al., Conference Record of 1992 IEEE Nuclear Science Symposium, October 25-31, Vol. 1, p. 563-565.

[2] N. Dobeck, "Precision Power Supply Control Module," Conference Record of the 1991 IEEE Particle Accelerator Conference, May 6-9, Vol. 2, p. 935-937, IEEE91Ch3038-7.

[3] N. Dobeck, et al., "Precision 32 Channel Power Supply System," Proceedings of the 1990 Linear Accelerator Conference, September 10-14, p. 490-492, LANL LA-12004-C.

[4] W. Merz, et al., "Early Operations and Reliability Experience With the CEBAF DC Magnet Power Supplies," to be published in Proceedings of the 1995 IEEE Particle Accelerator Conference. 